\title{
Slaughterhouse workers exposed to cold: proposal of reference thermography values for hands
}

\author{
Márcia Rosângela Buzanello ${ }^{\mathrm{a}, \mathrm{b}^{*}}$ and Antônio Renato Pereira Moro ${ }^{\mathrm{c}, \mathrm{d}}$ \\ ${ }^{a}$ Post-graduation Program in Production Engineering, Laboratory of Biomechanics, Federal \\ University of Santa Catarina, SC, Brazil; \\ ${ }^{b}$ Department of Physical Therapy, State University of West of Paraná, Cascavel, PR; \\ ${ }^{\mathrm{c}}$ Post-graduation Program in Production Engineering, Laboratory of Biomechanics, Federal \\ University of Santa Catarina, SC, Brazil; \\ ${ }^{d}$ Department of Physical Education, Laboratory of Biomechanics, Federal University of Santa Catarina, SC, \\ Brazil.
}

\begin{abstract}
The cold environment is an indispensable for slaughtering and processing in the poultry industry In field studies it was observed that a large percentage of workers of this sector have hand contact with the cold chicken and / or frozen, have high complaints prevalence of pain and discomfort, mostly in the hands. The contact of human skin with a cold surface may cause pain, numbness and risk of skin damage. Currently, although the use of infrared thermal imaging has been useful in identifying normal and abnormal patterns of heat distribution on the surface of the body. However your use for work tasks and to assess the potential development of injuries related to it has been limited. Based on the physiological responses can be objectively evaluate the effects of the task demands of work and thus contribute to the development of effective strategies for ergonomic intervention. The methodology will be used to evaluate the subjective thermal sensation with analogue scale of ASHRAE and the infrared thermography in the dorsal and palmar hands. Thus the objective of this research is to propose reference values for thermographic hands within limits of comfort.
\end{abstract}

Keywords: Artificial cold, Ergonomic, Infrared thermography

\footnotetext{
* Correponding author. Email: mrbuzanello@yahoo.com.br Adrress: General Rondon, 1559, Zip code 85901-160, Toledo, PR, Brazil
} 


\section{Introduction}

Due Brazil is a country with tropical climate. It has a litlle activities in occupational exposure to cold limited to the artificial environment, featured the slaughterhouse industry. According with UBABEF [26] Brazil in 2010 returned to the ranking of largest exporter of chicken meat in the world, and therefore employing a large number of workers for their slaughter and processing. Moreover, the concerns of workers and unions with the growing trend of more and more work at lower temperatures.

Occupational exposure to cold is an indispensable factor for slaughtering and processing in the poultry industry, often leading to thermal discomfort. In field studies it was observed that a large percentage of workers who have hand contact with the cold chicken and / or frozen, have high prevalence of complaints of pain and discomfort mostly in the hands Buzanello [18]; Buzanello, Moro and Martins [19] and Holmér [9]. An environment is defined as cold when heat loss is higher than normal. Where thermoregulatory actions are required in advance and compensatory [9]. The cold can occur by air, water or in contact with solid materials. Clothed or unclothed parts of the body can be locally exposed to cold (hands, face and legs) or the whole body. The cold stimulus can be characterized by its duration, intensity and repetition time.

Restricting to the scope of human activity in a occupational perspective in the exposure to cold, a central theme of this study, the good performance of the individual tends to decrease causing problems of health, safety and productivity. The combination of environmental variables and individual factors can trigger in the cold workers exposed a multitude factors of thermal stress. Effects can be classified in two groups, the global cooling of the body and the various forms of localized cooling. In the present work has as main complaints of discomfort located in the workers hands.

The stress caused by cold light causes thermal discomfort, resulting in complaints of discomfort from the cold and even pain. The discomfort may represent a distraction that can reduce mental alertness, increasing the reaction time and number of errors and consequently decrease the quality of work and even result in accidents [12].

Taking into account that the thermal environment is one of mains focus of interest of ergonomics and since a large population of the slaughterhouse poultry industry is exposed to environmental variables that contribute to the sensation of thermal discomfort. There is a side by need to comply with strict standards to ensure the conservation of the product and in the other hand workers exposed to a sum of environmental variables that do not always ensure your comfort. So it can be considered a conflict between the rules of food safety which sets maximum product temperatures below the comfort zone, health, safety and well-being and health and safety standards.

So it is important to know about the environmental conditions that could to cause this state. As well as observing the type of work and exposure of the individual to that situation.

Thus this research will use as tool the infrared thermal imaging based on physiological responses to it can objectively evaluate the effects of the demands of work task, and thus contribute to the development of effective strategies for ergonomic intervention.

Cold receptors are more prevalent than in the skin heat receptors and the density of cold receptors is greater on the face and upper limbs. As the hands are anatomically and physiologically more susceptible to heat loss. What makes evident the need for studies with special attention of hands. According to Iida [8] job strain is strongly influenced by adverse environmental conditions such as extreme temperatures, noise and vibration. These factors cause discomfort, increase the risk of accidents and can cause considerable damage to health. Grandjean [3] adds that in the comfort disturbances are accompanied by functional changes that affect the whole body.

Exposure to cold has been shown to involve a variety of different subjective complaints ranging from discomfort to symptoms associated with cold. Coldrelated diseases are defined as diseases caused by cold or symptoms that get worse during cold exposure.

From the physiological point of view the cold actives the human thermoregulatory system, while from a psychological point of view, because the cold wind chill unpleasant or even pain induced by cold, which is experienced as stressful. After the severe cooling between 5 and $10 \mathrm{~min}$, and finger skin temperatures below $12^{\circ} \mathrm{C}$, an anomalous reaction occurs, the cold induced vasodilation (CIVD): the blood on the fingers vasodilation, which increases blood flow and temperature of the fingertips. After this CIVD, blood vessels begin to re-contract again, leading to drops in temperature of the skin [7]. According to Lewis [24] that cyclical change in skin temperature, the repeated periods of vasodilation and vasoconstriction, has also been called "hunting response". 
Usually the links between arterial and venous circulation are made through the capillaries, however, direct links, arterio-venous anastomoses (AVA) between the arterial and venous network are found in the fingers, elbows, lips, cheeks and nose, however is that the hands are in contact with the cooling product. It was found that the cold-induced vasodilation only occurs at sites of AVA, as well as many individual factors such as age, sex, physical and mental health, adaptation and acclimatization to cold affect the occurrence of cold-induced vasodilation [7]. Like the sensation of the skin depends on several factors other than temperature of the temperature such as room temperature before exposure to cold, the skin region, individual sensitivity to cold, so cold adaptation.

The cold stress is defined as the integrated effect of a combination of climatic factors that affect the heat balance of the body. The stress caused by cold can be classified according to various types of cooling: cooling the entire body (as a function of metabolic heat production and the various forms of heat loss), extreme cooling (especially the fingers), cooling convection (direct action of wind on the skin), cooling by contact (due to contact with cold materials) and airway cooling (cooling of the airways) [9]. The effects of cold on human health are dependent mainly of the basic parameters of environmental factors (temperature, wind, humidity), the degree of activity (eg, light work or heavy) and clothing used.

Depending on the interaction of these variables by cold stress causing local or general cooling can occur. This cold stress can result in a variety of different effects of the injuries to discomfort from the cold. In a cold environment can occur reducing the mental performance [17] or physical [14]. Even in general and moderate cooling of the entire body, which causes surface cooling, but unmarked deep cooling of the body, greatly increases the postural balance, indicating an impaired postural control [25]. Thus the objective of this research is to propose reference values for thermographic hands within limits of comfort.

\section{Method}

This research went aproved to the Ethics Committee on Research involving Human Beings of the State University of West of Paraná - UNIOESTE. Will be used an analogue scale to evaluate the subjective thermal sensation and infrared thermography to the evaluate a physiologicals criterias.

\subsection{Subjects}

The study will be conducted in a poultry slaughterhouse in the southern region of Brazil. The sample will be composed by 300 workers of cutting and shipping sectors. These sectors were classified with artificially cold, environment temperature equal or not exceeding $12^{0} \mathrm{C}$.

\subsection{Exclusion criteria}

No smoked or consumed alcohol within 8 hours before the procedure, presence of abnormality in the skin (scars, dermatitis), fractured hand / wrist, or anatomical abnormalities in the hands and wrists.

\subsection{Thermal imagens}

The thermographic imaging will be obtained by a portable infrared thermography Camera ThermaCAM ${ }^{\circledR}$ E320, FLIR, with a resolution of $320 \times 240$ pixels, $4 \mathrm{x}$ digital zoom, thermal sensitivity of $<0.10^{\circ}$ $\mathrm{C}$ to $25^{\circ} \mathrm{C}$ and an accuracy of $\pm 2{ }^{\circ} \mathrm{C}$. All images will be corrected using a factor of emissivity of 0.98 (human skin).

The thermograph will be positioned one meter high, $90^{\circ}$ angle and a distance of 1 meter and 20 centimeters over the region of interest (ROI). The individual will stand with their arms outstretched in front of the body and will make an approach movement toward the feet, fingers outstretched, hands open and away and keeping the middle finger parallel. Will be two thermographic images: view of the dorsal and palmar Figures 1 and 2 respectively.

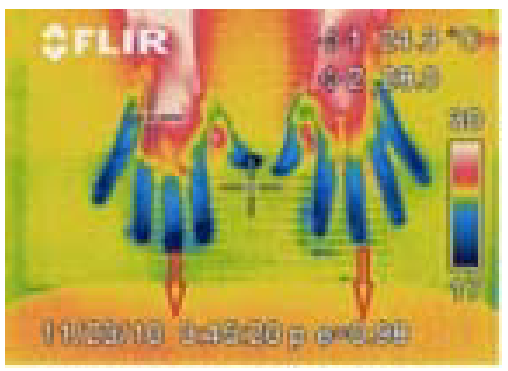

Figure 1 - Thermogram: dorsal view 


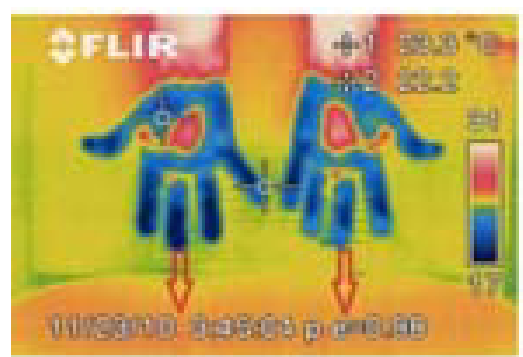

Figure 2 - Thermogram: palmar view

\subsubsection{Thermographic analysis}

The analysis of thermographic images will performed by the software Quick Report. Bordering a geometric design with the tool "area." This design should cover as much as possible to the dorsal, palmar and fingertip, as shown in Figures 3 to 6 .

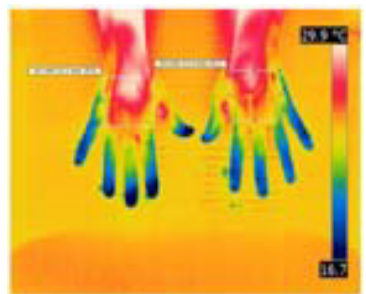

Figure 3 - Dorsal region

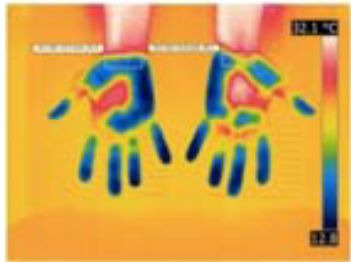

Figure 5 - Wrists regions

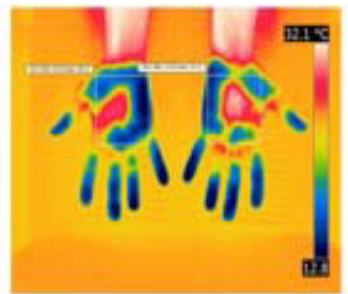

Figure 4 - Palmar region

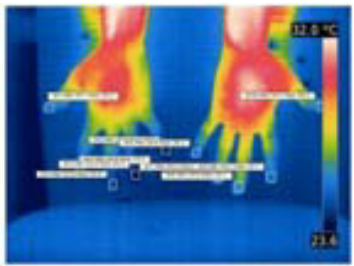

Figure 6 - Fingertips regions
Defined the area to be measured will be used the export feature to Excel. The uploaded file is a data matrix in which each pixel is assigned a measure of temperature. According to Plassman [20] recommends the use of an array of at least $8 \times 8$ pixels, resulting in 64 measures. In the case of the operation led to five fingers on each hand matrices, with an average of 79.8 measurements (pixels) per area. Drew is the mean of each array and the average of the averages (5) generated an average temperature of the palmar fingertips, the right hand, left and both variable (which is the average temperature of the right and left hand). In the case of the wrist, the palmar region and back of hands obteu only a geometric area for each hand. The process of exporting to excel took place in the same way. All measurements were exported to SPSS where they were processed statistics.

\subsection{Visual analogue scale}

The subjective variable sensation of thermal comfort is evaluated by for the American Society of Heating, Refrigeration and Air-Conditioning Engineers, Inc. (ASHRAE), which uses a seven-point psychophysical scale for assessing thermal comfort. The points range from psychophysical +3 (very hot) to -3 (very cold). The individuals will select an alternative to localized thermal sensation of hands, Figure 7.

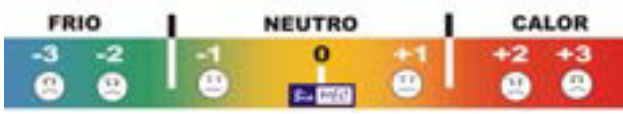

Figure 7 - Thermal sensation scale Source: ASHRAE (1997), adapted by Biomec

The individuals will be also mark with an $\mathrm{x}$ the locations of the hands that feel this discomfort, Figure 8.

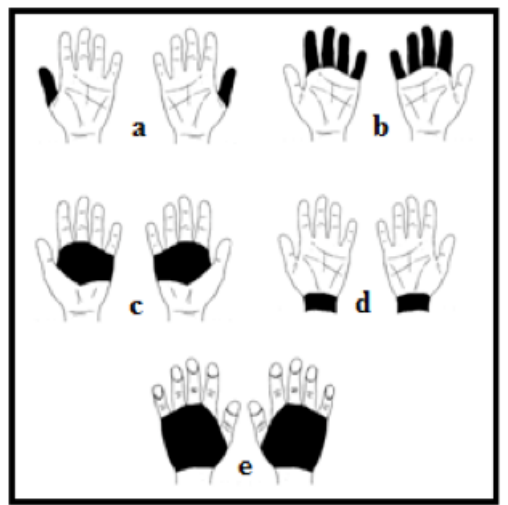

Figure 8 - Places of local discomfort by cold

\subsection{Data analysis}

The statistical analysis will be tested as average temperatures obtained from the thermograms of the various anatomical regions of interest (dependent variable) obtained from subjects that will be divided into different categories. To test mean differences between the categories will be used Student's $t$ test. 
In the case of two variables of quantitative analysis will be performed correlation analysis or regression analysis.

\section{Expected result and discussion}

The expected results are the development of thermographic reference values within limits of comfort and guidance of risk prevention strategies in biomechanics and ergonomics to workers exposed to articial cold in slaughterhouses.

Nicol and Humphreys [13] considered problematic to define ranges of acceptable conditions around a target temperature. The authors argue that the size of their comfort zone, in purely physical terms. Depends on the balance between external temperatures of the individual and the possibility of resorting to behavioral mechanisms that reduce the discomfort. In a situation where you can not change clothes or activity, and where ventilation can not be controlled, the range of comfort will be narrower, varying only $\pm 2^{\circ}$ $\mathrm{C}$ around the mean. On the other hand, when one can use adaptive strategies, possible and appropriate, the comfort zone may be considerably wider.

Numerous studies about the contact of human skin with a cold surface; found that it can cause pain, numbness and risk of skin damage Daniels [5]; Havenith et al. [6], Chen et al. [4]. Moreover, the reduction in tactile sensitivity Provins and Morton [15] and manual dexterity Geng et al. [22] Geng [21] and Powell et al. [23] associated with the cooling of the skin also greatly influence our ability to execute routine manual tasks required by workers in cold environments a efficient and safe way Enander [1] and Havenith et al. [6].

According to ISO 11079-1993 (E) Annex B.1 [11] local cooling caused by convection, radiation or heat loss by contact, should not result in temperatures of hands and the skin below $15^{\circ} \mathrm{C}$ and $24^{\circ} \mathrm{C}$, respectively under such circumstances the temperature of the fingertips can be several degrees lower.

In this study, complaining of discomfort was higher in the cold surface of hand contact with the product. In this case the garment can be added, but the pace of work can not be controlled by the worker. However, for the gloves, it is worth noting that it should be effective enough to create a mechanical barrier against the cold. However, it should not interfere with the performance. Thus the quality of the gloves is of principal importance to ensure the comfort and worker performance.
Holmér [9] found problems associated with occupational exposure to cold as the thermal discomfort and sensation of pain, especially in the extremities, decreased performance due to cooling of the hands, cold muscles or overall cooling of the body, or difficulty caused by the garment protection against the cold as weight, volume, friction, etc. and effects on human health, such as injuries caused by cold and high risk of accidents.

The exposure to physical work, high repeatability and temperature is typical in cold stores in meat processing industries, where most part of facilities of the production process are cooled for reasons of hygiene. So when the heat loss in the human body is greater than the gain, the thermoregulatory system may not be able to compensate for heat loss leading to conditions of cold stress. Exposure to cold working environment is a significant risk and represents an adverse effect on comfort, performance and human health Holmér [10]; Parson [16].

\section{Acknowledgements}

Thanks to UNIOESTE and UFSC for financial help.

\section{References}

[1] A.Enander. Performance and sensory aspects of work in cold environments: a review. Ergonomics, 27(1984) 365-78.

[2] American Society of Heating, Refrigerating and AirConditioning Engineers, Inc.- ASHRAE. Physiological principles for comfort and health. In: Handbook Fundamentals. Atlanta, 2001. p. 8.1 - 8.2.

[3] E.Grandjean. Manual de ergonomia: adaptando o trabalho ao homem. Tradução de João Pedro Stein, Porto Alegre: Bookman , 1998.

[4] F.Chen, H. Nilsson and I. Holmér. Cooling responses of finger in contact with an aluminium surface. Amer Ind Hyg Assoc J. 55(1994) 218-222.

[5] F. Jr.Daniels.US Army Natick, MA. Quartermaster Research and Development Center. Contact cooling of the hand at $-20^{\circ} \mathrm{F}$. Technical report EP-22. 1956.

[6] G. Havenith, E.J.G.Van de Linde and R. Heus. Pain, thermal sensation and cooling rates of hands while touching cold materials. Eur J Appl Physiol. 65 (1992), 43-51.

[7] H.A.M. Daanen. Finger cold-induced vasodilatation: a review. Eur J Appl Physiol, 89 (2003), 411-426.

[8] I. Iida, Ergonomia: projeto e produção, (2 ed.), Edgard Blücer, São Paulo, 2005.

[9] I.Holmér. Extremity cooling and performance. In: I. Holmér ed. Work in Cold Environments. Undersökingsrapport. National Institute of Occupational Health, Solna, Sweden. 31(1994), 49-55. 
[10] I.Holmér. Prevention of cold injuries. Hypothermia - cold induced injuries, NR. 1997-00-060, The National Board of Health and Welfare, Stockholm, Sweden. 1997.

[11] ISO 11079 (2007). Ergonomics of the thermal environment Determination and interpretation of cold stress when using required clothing insulation (IREQ) and local cooling effects. International Standards Organisation, Geneva.

[12] J. Hassi, O. Ervasti, K. Juopperi, H. Rintamäki, R. Pihlajaniemi and T. Linna. Lifetime incidence of frostbite, its Association with cold induced white fingers, vibration exposure and outdoor activity in young Finnish men. Problems with cold work. In: Proceedings from an international symposium held in Stockholm, Sweden,GrandHôtel Saltsjöbaden, November 16-20, 1997.

[13] Nicol, J. F.and M.A.Humphreys. Adaptive Thermal Comfort and Sustainable Thermal Standards for Buildings. Proceedings of Moving Thermal Comfort Standards Into the $21^{\text {st }}$ Century. p. 45-59. Windsor - UK. 5-8 April. 2001.

[14] J. Oksa. Cooling and neuromuscular performance in man [Doctoral]. University of Jyväskylä, 1998.

[15] K.A.Provins and R. Morton. Tactile discrimination and skin temperature. J Appl Physiol; 15(1960)155-60.

[16] K.C. Parsons. Working practices in the cold: measures for the alleviation of cold stress. In: Proceedings from First International Symposium on Problems with Cold Work. Organized by National Institute for Working Life, 1997; Solna Sweden.

[17] L. A. Palinkas. Mental and cognitive performance in the cold. Int J Circumpolar Health, 60(2001):430-9.

[18] M.R.Buzanello. Influência de variáveis ambientais em frigorífico da unidade climática Subtropical Sul sobre os trabalhadores expostos a baixas temperaturas, Master dissertation, Federal University of Santa Catarina, 2003.
[19] M.R. Buzanello, A.R.P. Moro and C.V.B. Martins. Impact of musculoskeletal diseases in slaughterhouse's workers exposed to cold in southern Brazil. In: Proocedings of the the $9^{\text {th }}$ Pan Pacific of Conference on Ergonomics. Kaochung -Taiwan, 07-10-nov, 2010.

[20] P. Plasmann, E.J.F. Ring and C.D. Jones. Quality assurance of thermal imaging systems in medicine. Thermol. Int., 16(2006), 10-15.

[21] Q. Geng,E.Karlsson and I.Holmér. Manual performance after gripping cold surfaces with and without gloves. In: Proceedings of NOKOBETEF 6 and $1^{\text {st }}$ European conference on protective clothing. Sweden. May 7-10, 2000, pp. 208-211

[22] Q. Geng. Hand cooling, protection and performance in cold environments. Doctoral thesis, Lulea University of Technology. Arbete och Ha"lsa, 2001:4. Stockholm: National Institute for Working Life.

[23] S. Powell and G.Havenith. Cold Surface Research Group. The effects of contact cooling on manual dexterity and cooling of the hand. In:Proceedings of the 9th ICEE Ruhr Conference. Germany: Ruhr-University Bochum, 2000, p. 185-8.

[24] S.T. Lewis. Observations upon the reactions of vessels of the human skin to cold. Heart. 15(1930), 1031-1034.

[25] Mäkinen, T. M. and Hassi, J. Health Problems in Cold Work: Review article.Industrial Health, 47(2009), 207-220.

[26] União Brasileira de Avicultura - UBABEF. Exportações brasileiras de carne de frango, 09/12/2010. Available in: http://www.abef.com.br. Retrieved from: 10/12/2010. 